CuPAUAM. 19-1992 9-31

\title{
ACERCA DE UNA POSIBLE JERARQUIZACION Y ESPECIALIZACION ECONOMICA EN LOS ASENTAMIENTOS ARGARICOS DE LA PROVINCIA DE ALMERIA
}

\author{
C. MAROTO BARCHINO
}

\section{Resumen}

El objetivo de nuestro trabajo consiste en aproximarnos a una posible jerarquización en el grado de desarrollo económico alcanzado por los asentamientos argáricos de la provincia de Almería. Analizaremos su concordancia o no con una superestructura política y con unos intercambios comerciales regulares y organizados. Contrastaremos si este comercio pudo llevarse a cabo debido a una especialización económica diferente para cada uno de los hábitats.

\section{Summary}

The objective of this work consists on an approachment to a possible hierarchy in the economic degree reached by the argaric settlements in Almería province. We shall analyse its possible agreement with a political overstructure and regular and organised trade exchanges. We shall check out if this commerce could be carried out because of an economical specialization different for each settlement.

La bibliografía existente, en torno a este tema que traemos a colación, defiende la existencia de una estructuración jerárquica de los asentamientos argáricos (al menos en determinadas áreas). El desarrollo económico-societario alcanzado podría explicarse con la existencia de diferencias cualitativas en las actividades productivas de cada uno de los hábitats. Así, mientras algunas comunidades estarían abocadas a un mantenimiento bajo mínimos, agricultura de subsistencia y/o explotación minera, otras se beneficiarían de este orden "impuesto" concentrando actividades especializadas de transformación de los productos obtenidos por aquellas, y beneficiándose de esa producción alcanzando niveles de consumo muy por encima de las necesidades básicas.

De este modo, verbigracia, se expresa V. Lull $(1983,446,438,456)$ "comunidades complementarias", en función de una metalurgia desarrollada que impone nuevos patrones de asentamiento, desarrollo de los intercambios comerciales y que compone un nuevo modelo societario. En esta misma línea se situó Corral Cañón (1984) quien abordó el problema que desde otras variables pretendemos presentar aquí. Su estudio, que ha constituido un modelo metodológico 
para nuestro trabajo, concluye en la existencia de una voluntad política en la elección de los asentamientos y en un control de unos yacimientos significativos sobre los recursos de otros, toda vez que "las diferencias de recursos naturales no sirven para explicar los diversos esquemas de asentamientos y cuando las tradiciones locales no valen tampoco como explicación definitiva del fenómeno" (Corral Cañón,1984,205).

En definitiva, y como desarrollo ulterior de las tesis expuestas, tenemos configurada la cultura argárica a niveles societarios "estatales" (Lull y Estévez,1986,451) introduciéndose así un salto cualitativo con respecto a anteriores afirmaciones de Lull, para quien en 1983 la cultura argárica estaría organizada tan sólo como una jefatura (Lull,1983,456).

En último extremo, el tema se inscribe en la problemática evolución social del III al II milenio en el SE peninsular. Cuestión debatida por autores como R.W. Chapman (1978,1982,1987), Gilman (1981,1987), Ramos (1981), C. Mathers (1984) o el mismo Lull (1983). Precisamente el cambio del Calcolítico al Bronce supone la aparición de estructuras sociales complejas (entre otros aspectos) pero ¿en qué grado?, ¿qué variables entran en juego?, ¿cuáles son sus relaciones?.

En este contexto hemos decidido realizar un pequeño análisis, que permita contrastar algunas de las afirmaciones emitidas acerca de la complementariedad que se supone entre asentamientos argári$\cos$, sobre la que se sustenta la hipótesis de una estructura estatal para esta cultura. No plantearemos cuestiones sociales, ni disquisiciones en torno al concepto de Estado, necesaria e ingente labor. Por el contrario, constituye el objetivo de estas líneas, en la medida de lo posible dada la limitación de la información disponible, una clasificación siguiendo criterios económicos de algunos yacimientos adscribibles al Bronce Pleno del SE peninsular, en la Provincia de Almería concretamente. Pero no intentamos establecer el grado de complejidad de los asentamientos elegidos para explicarlos en sí mismos, sino en función de la interrelación existente con el conjunto de ellos en suma, atendiendo a su distribución en el espacio, e incluyendo las matizaciones cronológicas que sean posibles.

Queremos, en un principio, leer a partir de las evidencias y restos arqueológicos el grado de adelanto en las actividades extractivas, de transformación, producción y consumo de estas comunidades argáricas. Este análisis lo haremos a partir de un conjunto de variables aplicables a todos y a cada uno de los hábitats por igual.

Los yacimientos que hemos elegido son: El Oficio, Cerro de Enmedio, El Argar, Gatas, Fuente Vermeja, Lugarico Viejo, Fuente Alamo, Peñón de la Reina, El Picacho, Cabezo de San Miguel, Herrerías-Almizaraque, La Pernera, Vera, Teresa, La Panalera, La Losa, La Risca, Cerro Castellón, Peñicas Negras, Cerro del Castillo y Cerro del Fuerte (FIG.I). Todos ellos están situados en la actual provincia de Almería, en las cuencas de los ríos Jauro-Antas, Bajo Almanzora , Aguas y Andarax exceptuando El Picacho en el tránsito a las altiplanicies granadinas. La zona nos parecía susceptible de una mayor atención puesto que se considera la zona nuclear de la cultura (Lull,1983,231; Chapman et alii ,1987,12) aunque Martínez Navarrete $(1989,462)$ sostiene que no existen evidencias para probar tal información.

\section{VALORACION DE LA INFORMACION DISPONIBLE}

Ahora bien, como consideración previa de este trabajo, debemos partir de una situación insoslayable que merma considerablemente la validez de cualquier afirmación. Esto es, contamos con una información diferente para cada uno de los yacimientos. En primer lugar, muchos de ellos sólo están prospectados y no siempre con carácter sistemático, y aquellos que están exca- 


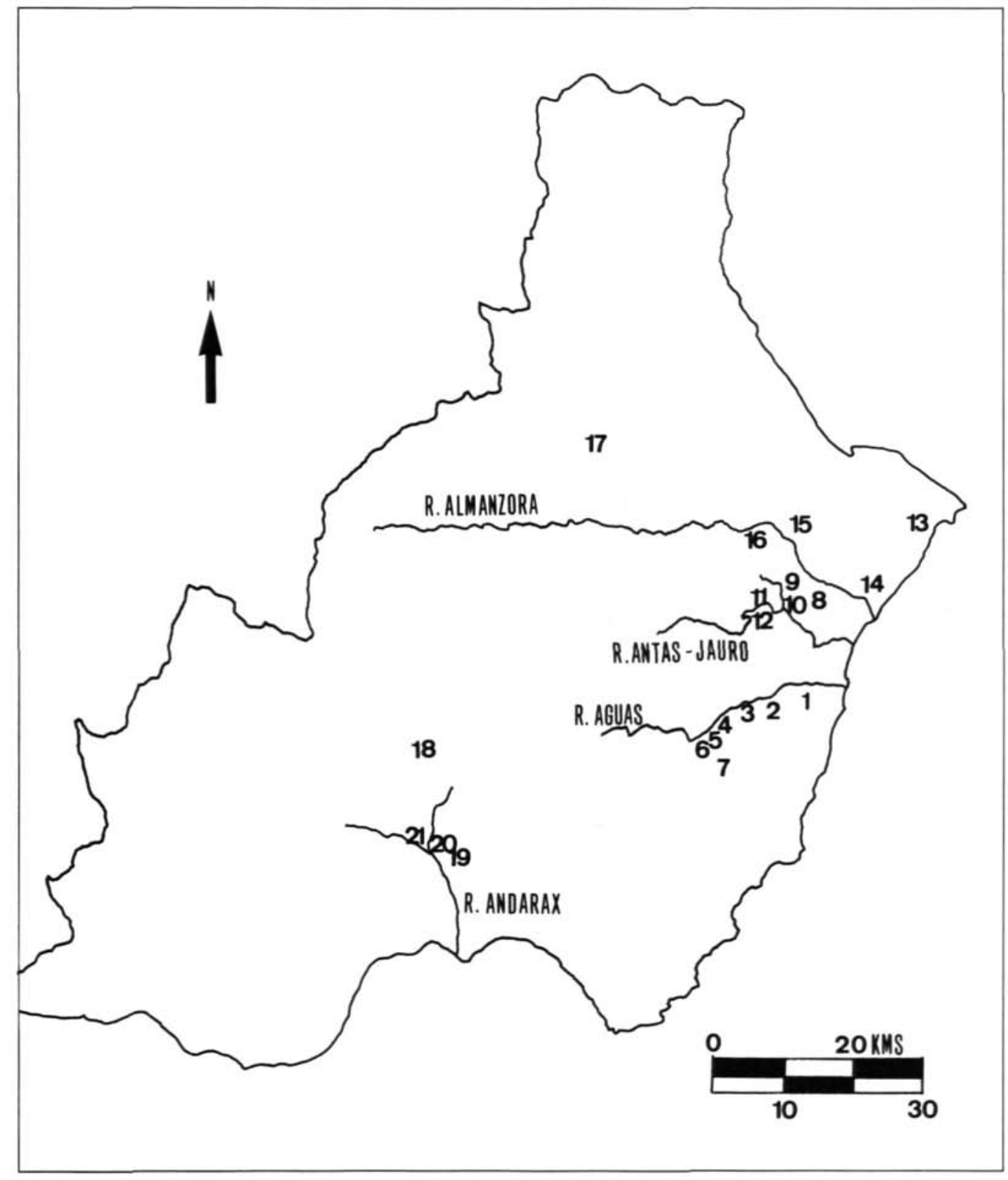

Figura $1^{\circ}$. YACIMIENTOS ARGARICOS DE LA PROVINCIA DE ALMERIA. 1. Gatas, 2. Teresa, 3. La Panalera, 4. La Losa, 5. La Risca, 6 Cerro Castellón, 7. Peñicas Negras, 8. Vera, 9. La Pernera, 10. El Argar, 11. Fuente Vermeja, 12. Lugarico Viejo, 13. El Oficio, 14. Herrerías-Almizaraque, 15. Fuente Alamo, 16. Cabezo San Miguel, 17. El Picacho, 18. Peńón de la Reina, 19. Cerro de Enmedio, 20. Cerro del Castillo, 21. Cerro del Fuerte. 
vados lo fueron en su mayoría por los Hermanos Siret con lo cual debemos ceñirnos a sus publicaciones, muchas veces preciadas por el lujo de detalles con respecto a determinados aspectos pero siempre parciales, como Leira Jiménez (1987) pudo comprobar .

Con el fin de tener unos parámetros fijos y objetivos para la estimación de los datos, entresacados de las distintas publicaciones, y de la respectiva documentación cartográfica (topográfico, geológico, metalogenético y de cultivos y aprovechamientos), hemos contado con una ficha sinóptica confeccionada por el Dr.Sánchez Meseguer y el equipo del Proyecto Arxeos que hemos adaptado a este área peninsular y al periodo cultural que tratamos.

Esta ficha consta de cuatro apartados. En el primero de ellos se recogen las noticias de tipo general referentes al término municipal, Hoja del mapa del I.G.C., longitud, latitud, altitud, área cultural, cronología y bibliografía, tipo de yacimiento y ubicación.

Un segundo apartado muestra la existencia o no de infraestructuras (defensas naturales, artificiales, obras hidráulicas, ordenación urbana y estructuras de habitación). La información referida a los recursos existentes en el entorno, (fluviales, manantiales, minerales, vegetales, suelos, vías) queda incluida en un tercer apartado. Por último, y en cuarto lugar se registra la información que alude a los materiales recuperados (piedra tallada, pulimentada, restos de cocina, cerámica, objetos de barro, mineral, escorias, objetos metálicos, metalúrgicos, materiales exóticos, adornos).

Para la valoración cuantitativa se considera que la importancia de los distintos bloques o apartados es diferente. De tal forma que al primer bloque se le asigna un valor o porcentaje del $5 \%$, al segundo el $15 \%$ y un $30 \%$ y un $50 \%$ al tercer y cuarto bloque respectivamente.

El porcentaje de información de cada bloque se calcula en función de una fórmula $\mathrm{PI}=\mathrm{n} 2(\% \mathrm{a}) / \mathrm{N}$, siendo $\mathrm{PI}$ el porcentaje de información , $\mathrm{N}$ el número de datos que se evalúa en cada parte, $\mathrm{n} 2$ el número de datos que proporciona información en cada parte y \%a el porcentaje asignado a cada parte.

De esta forma, revisando el número de datos disponible para cada uno de los yacimientos se considera que la información es:

1. Excelente: Más del $80 \%$

2. Buena: Entre el 61 y el $80 \%$

3. Suficiente: Entre el 41 y $60 \%$

4. Poca: Entre el 21 y el $40 \%$

5. Deficiente: < del $20 \%$

El resultado de la aplicación de esta ficha sinóptica a los yacimientos que tratamos, considerando la información correspondiente al poblado, es el siguiente:

EXCELENTE: Fuente Alamo, Gatas, El Oficio

BUENA: El Argar, Lugarico Viejo, Fuente Vermeja

SUFICIENTE: El Picacho, Peñón de la Reina

POCA: Cerro de Enmedio

DEFICIENTE: Cerro del Castillo, Peñicas Negras, Teresa, La Panalera, La Losa, La Risca, Cerro del Fuerte, La Pernera, Vera, Herrerías Almizaraque y Cabezo San Miguel, Cerro Castellón.

\section{METODOLOGIA}

Para abordar la cuestión principal de este trabajo, la clasificación económica de los hábitats que tratamos, hemos establecido una serie de criterios que nos permitieran discriminar los 
distintos grados alcanzados en las diversas actividades desarrolladas por estas comunidades argáricas.

Ya Corral Cañón $(1984,198)$, que como hemos dicho se propuso este mismo trabajo, distinguió tres tipos de yacimientos: Poblados agrícolas o mineros, yacimientos intermedios con actividad metalúrgica y yacimientos principales. Las variables utilizadas por este autor fueron la presencia/ausencia de dientes de hoz, útiles metalúrgicos, objetos metálicos y instrumentos relacionados con la actividad minera. Nosotros hemos querido aumentar el número de variables con el fin de aquilatar con mayor precisión la clasificación económica de estos hábitats.

De esta forma, exponemos que las distintas comunidades, según los restos y evidencias arqueológicas, habrían alcanzado un nivel "alto" de desarrollo (terciario) cuando estuvieran presentes objetos exóticos o hubiera referencias a la existencia de excedentes productivos. El nivel medio (secundario) está representado por yacimientos en los que se ha desarrollado:

- Caza mayor

- Transformación de productos agrícolas

- Utiles metalúrgicos

- Objetos metálicos

- Actividad textil

- Industria ósea

Aquellos yacimientos en los que tan sólo tuviéramos información acerca de actividades de recolección de frutos, moluscos, caza menor y pesca, consumo de animales domésticos, recolección agrícola, sementera, explotación minera o trabajo de la madera supondrían un nivel bajo o primario.

En definitiva, en el primer grupo tendríamos comunidades que tienen cubiertas las necesidades primarias y que desarrollan industrias de transformación de materias primas orgánicas e inorgánicas, contando con excedentes de producción y posibilidad de derivar parte de la riqueza hacia la obtención de bienes de prestigio. Aquellos hábitats cuyas actividades primordiales estén destinadas a la transformación y producción de objetos manufacturados compondrán el grupo de grado intermedio. Mientras que el grado más bajo estará integrado por yacimientos en los que únicamente se cubren las necesidades básicas de subsistencia y/o se desarrollan actividades extractivas mineras.

Esta gradación ha sido sistematizada de forma concluyente y explicativa para el Tercer milenio por C.Galán (et alii,1988,69-105) cuya metodología hemos adaptado a este estudio.

\section{APLICACIONES Y RESULTADOS}

Consultada la bibliografía pertinente, y convenientemente analizados los restos y evidencias arqueológicas, podemos aproximarnos a un intento de clasificación entendiendo son yacimientos de nivel terciario o con un desarrollo de las actividades extractivas, de transformación y producción alto: El Oficio, El Argar y Fuente Alamo. Por su parte, Cerro de Enmedio, el Picacho, Gatas y Lugarico Viejo alcanzarían el nivel intermedio en el que se desarrollan preferentemente actividades de transformación. El resto de los yacimientos formarían la base amplia del nivel primario o bajo desarrollo económico, teniendo en cuenta que el número de comunidades adscritas a este último grado lo es en su mayor parte por la falta de materiales que permitan un análisis minucioso de los mismos. Tan sólo tenemos constancia en estos últimos de la recogida de fragmentos cerámicos y la constatación de estructuras constructivas, atribuibles a este segundo milenio únicamente por la cerámica asociada en superficie. 


\section{ANALISIS POR CUENCAS HIDROGRAFICAS}

Si procedemos a la evaluación de la escala jerárquica económica obtenida para cada una de las cuencas hidrográficas en que se sitúan los yacimientos que tratamos, estará en nuestra mano verificar el modelo de asentamiento de esta cultura y la reiterada apreciación de complementariedad interasentamientos.

Así, en la CUENCA DEL ANDARAX (FIG.2) hemos obtenido un nivel intermedio para el Cerro de Enmedio, mientras que los cerros del Castillo y del Fuerte sólo se sitúan en el grado de abastecimiento o autosuficiencia de los productos básicos, a pesar de que esta última apreciación es cuestionable puesto que para el cerro del Castillo no tenemos ningún tipo de información sobre restos de materiales que denuncien actividades económicas. En el caso del Cerro del Fuerte se mencionan exclusivamente fragmentos de crisol (Arribas, 1953-54,343).

Lull $(1983,274)$ supuso que el Cerro del Fuerte y del Castillo serían poblados orientados a la actividad agrícola mientras que el Cerro de Enmedio debido a la proximidad en Sierra Alhamilla de filones de plata y cobre debería su posición espacial a la extracción minera. Por Díaz Alvarez (1981 y 1984) hemos localizado los yacimientos en el Mapa de Suelos que acompaña en su publicación constatando que el Cerro del Fuerte y el de Enmedio se asientan en las proximidades de suelos aluviales y coluviales mientras que el Cerro del Castillo lo hace sobre rendzinas, todos ellos con un perfil A/C y por tanto sin sustanciales ventajas de unos respecto de otros. Pues aún suponiendo más productivos los suelos de vega, también lo son las rendzinas sobre margas y calizas. Por tanto la actividad agrícola no está condicionada por la edafología así como tampoco por las características climáticas semejantes en los tres yacimientos (18-19 grados de temperatura media anual y $200-250 \mathrm{~mm}$ de precipitación anual). Es más en el cerro de Enmedio supuestamente minero, contamos con la presencia de cereales, aunque las dificultades orográficas serían mayores.

De otro lado, y tomando como apoyo los materiales arqueológicos registrados, la actividad minera no está documentada en ninguno de los tres yacimientos. Por el contrario la actividad metalúrgica es significativa por la aparición de moldes en el Cerro de Enmedio (Molina Et Alii,1980; Schubart,1980) allí por lo tanto se llevaría a cabo la manufactura de los objetos metálicos. En el Cerro del Fuerte los fragmentos de crisol mencionados por Arribas (1953-54) suponen la fundición del mineral y podríamos admitir que su manufactura. Por tanto la hipótesis sostenida por Lull $(1983,278)$ acerca de "el complemento que los asentamientos de montaña pueden representar para los asentamientos de vega en cuanto a actividades minero-metalúrgicas" no puede ser demostrada, pero no por la significativa ausencia de materiales como este autor menciona, sino por los datos aportados por el Cerro de Enmedio, autosuficiente, y en el que se llevan a cabo actividades de transformación metalúrgica y textil.

El intercambio podría ser llevado a cabo con mineral en bruto, mineral decantado, o útiles metálicos, a cambio de cereales producidos en las comunidades que se asientan en las vegas. Pero, como hemos apreciado, la actividad agrícola no se ha detectado para estos yacimientos (bien es verdad que tan sólo están prospectados) y sí para los supuestos poblados mineros como Cerro de Enmedio. El traslado del mineral en bruto sería una posibilidad, pero éste no aparece ni en el Cerro del Fuerte ni en el de Enmedio y la principal vocación minera del último se ha puesto en entredicho por sus prospectores (Molina Et Alii, 1980,165). El mineral beneficiado podría haberse trasladado desde el Cerro de Enmedio pero en éste también se llevaban a cabo las manufacturas y por su parte el Cerro del Fuerte beneficiaba su propio mineral, aunque en nin- 


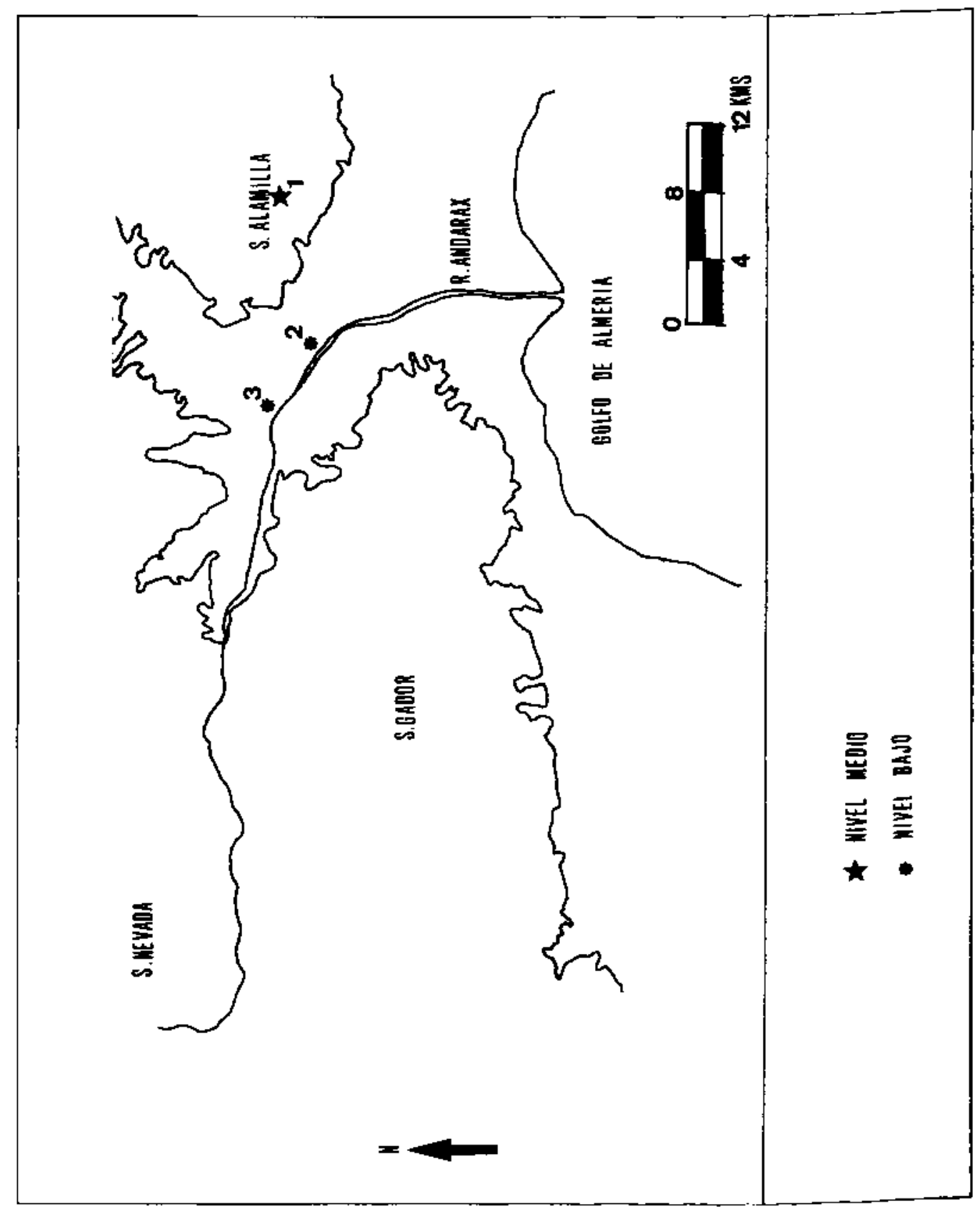

Figura $2^{\circ}$ : NIVEL ECONOMICO ALCANZADO POR LOS YACIMIENTOS DE LA CUENCA DEL ANDARAX (Tomado de Lull, 1983, modificado).

1. Cerro de Enmedio, 2. Cerro del Castillo, 3. Cerro del Fuerte. 
guno de los dos quedan restos de escorias. El intercambio a partir de objetos manufacturados no es contrastable puesto que allí donde se beneficia el mineral ¿por qué no manufacturarlo? y en caso contrario no tenemos testimonio de útiles manufacturados en el Cerro del Fuerte (en este caso ocasionado por la violación de la sepultura que aparece).

Lull en su obra de conjunto $(1983,429)$ entra en contradicción afirmando, de un lado la reiterada complementariedad entre asentamientos y el traslado del mineral reducido, y de otro lado decantándose por la explotación de la Sierra de Gador por parte de los habitantes del Cerro del Fuerte (ibidem,442). Por tanto no dependerían del abastecimiento del Cerro de Enmedio.

Un apunte final acerca de la cronología nos permite afirmar la contemporaneidad de estos asentamientos en un momento argárico indeterminado. Para Martínez Padilla (1986,312) tanto el Cerro del Fuerte como el Cerro de Enmedio tendrían una primera ocupación calcolítica. Por el contrario tanto Schubart $(1980,190)$ como Molina (Et Alii,1980,164) sostienen que el Cerro de Enmedio sería fundación argárica, entendiéndolo como fruto de la expansión de la cultura desde la zona que se considera cuna del Argar (el Bajo Almanzora) hasta la Alta Andalucía. A ello debemos unir la insistencia de ambos autores en el traslado de los moradores del Cerro de Enmedio al vecino Cerro del Rayo (con testimonio del Argar B en una sepultura).

\section{CUENCA DEL AGUAS}

El número elevado de yacimientos localizados (FIG.3) resulta engańoso en cuanto al nivel de información, puesto que la mayor parte de ellos sólo están prospectados y tan sólo Gatas de forma sistemática y parcialmente excavado. Por ello, y a la luz de los datos recogidos en la bibliografía existente (Siret, 1890 Algarra Esteban, 1955 y 1952; Chapman 1987; Tapia Garrido 1981) hemos clasificado a todos ellos en un grado bajo de autoabastecimiento primario exceptuando al citado Gatas en el que consideramos que las principales actividades fueron de transformación, aún cuando la modificación de esta conclusión sería avalada una vez que se lleve a término su excavación. Es más, su paso al grado alto o nivel terciario no estaría fuera de lugar por la aparición de marfil (Siret, 1890,222) a pesar de que no está constatada la existencia de excedentes de producción.

En cuanto a la variable cronológica, volvemos a tener dificultades cara a la precisión de la misma. Algarra Esteban, $(1952 ; 1955)$ el primer autor que da noticia de la mayor parte de este grupo de yacimientos, los asigna de forma genérica al periodo argárico. En el caso de Gatas (Chapman,1987,43) la ocupación se retrotrae al Neolítico y avanza hasta el Bronce Final.

No existe, desde el punto de vista de los recursos, una ventaja diferencial de unos yacimientos respecto a otros. Asentados en zonas aluviales y coluviales y sobre suelos pardo-calizos, según la aproximación que hemos hecho a través de la documentación de Díaz Alvarez (1981 y 1984), permiten en topografias suaves un buen aprovechamiento agrícola. Lull mismo $(1983,269,274)$ subraya estas posibilidades agrícolas en las cercanías del rio Aguas para Gatas, la Panalera, La Risca, Cerro Castellón, Teresa y en menor medida para La Losa. Mientras que Peñicas Negras debería su asentamiento a consideraciones estratégicas.

De otro lado, la proximidad a los filones metalíferos de cobre y plata es la misma tanto para unos como para otros. Gatas se encuentra tal vez más alejado de la obtención del mineral de cobre pero los restos encontrados en el yacimiento exponen que la distancia no fue un obstáculo. Antes bien, por el contrario, no hay evidencias de explotación minera y transformación metalúrgica en los poblados más próximos, debido indudablemente a la falta de excavaciones y 


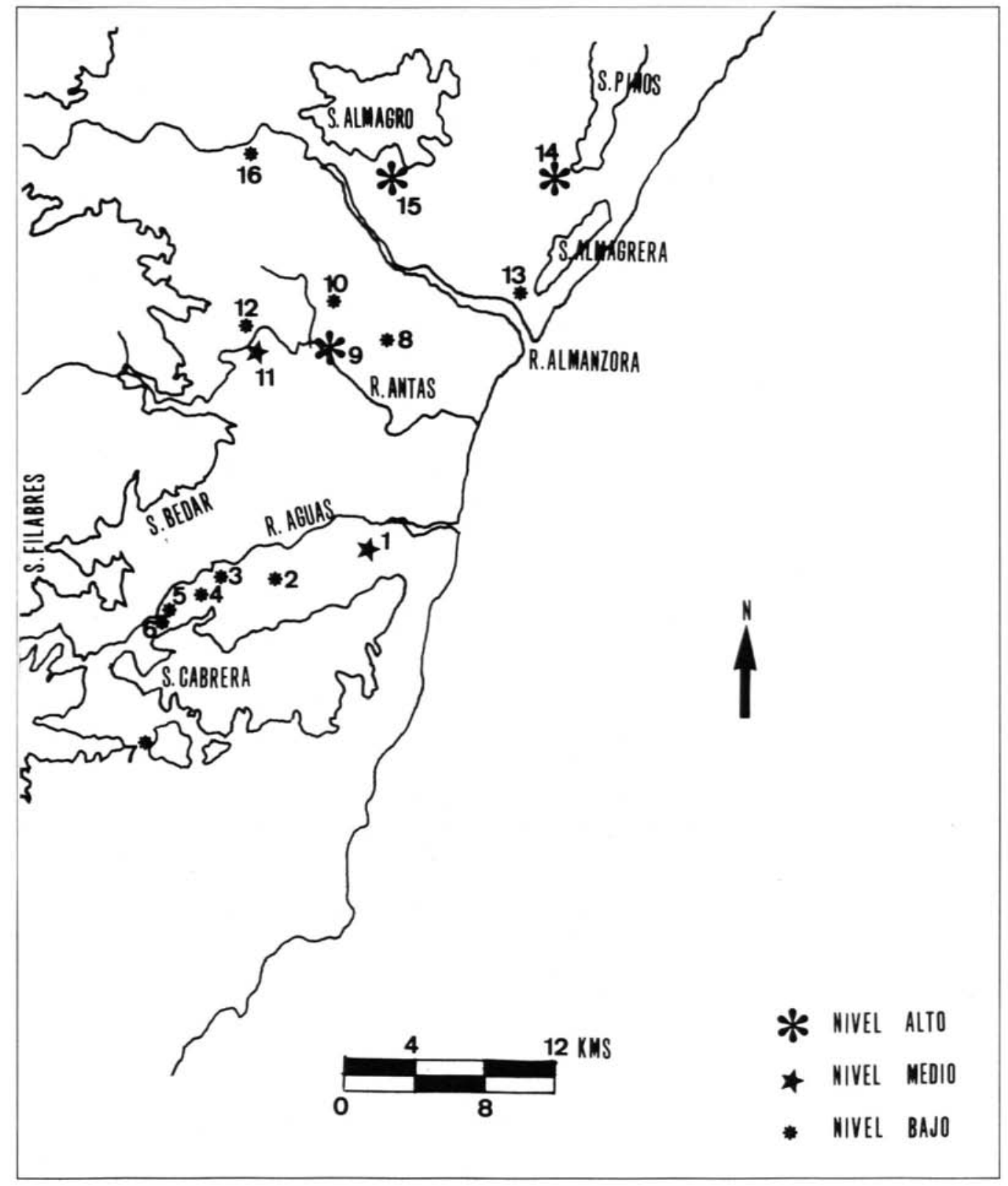

Figura 3: NIVEL ECONOMICO ALCANZADO POR LOS YACIMIENTOS DE LAS CUENCAS DEL JAURO-ANTAS, BAJO ALMANZORA Y AGUAS. (Tomado de Lull, 1983, modificado)

1. Gatas, 2. Teresa, 3. La Panalera, 4. La Losa, 5. La Risca, 6 Cerro Castellón, 7. Peñicas Negras, 8. Vera, 9. El Argar, 10. La Pernera, 11. Lugarico Viejo, 12. Fuente Vermeja, 13. Herrerías-Almizaraque, 14. El Oficio, 15. Fuente Alamo, 16. Cabezo San Miguel 
prospecciones sistemáticas. Es por ello que tampoco podemos hablar de un intercambio de mineral por grano en el caso de esta cuenca hidrográfica. Aún cuando se registraran actividades metalúrgicas y mineras en los yacimientos más próximos a los filones de cobre, la constatación de extracción, transformación y producción del cobre y plata en Gatas demuestra una actividad independiente.

No obstante, Lull $(1983,445)$, en función de esta potencialidad del medio en menas metálicas (Sierra de Bédar y Sierra Cabrera) considera a este grupo "fundamentalmente minero". Aunque páginas atrás (ibidem,234) apunta que tanto la minerometalúrgica como la agrícola serían actividades primarias, aunque la primera no contaría con los suficientes recursos de cobre. En cualquier caso, la hipótesis de Lull, que compartimos, es que formarían un grupo autónomo e independiente capaz de autoabastecerse con respecto al conjunto de hábitats del Almanzora y Antas-Jauro.

\section{CUENCA DEL ANTAS-JAURO}

De singular importancia por localizarse en ella El Argar, yacimiento epónimo, es reconocida como zona de recursos agrícolas potenciales de gran valor, existiendo una unidad en cuanto a la edafología en los asentamientos registrados (FIG.3). Todos ellos se ubican en suelos pardo-calizos o inceptisoles que limitan con Aridisoles de difícil explotación y escasa fertilidad. (Catálogo de suelos de Andalucía, 1984; Mapa de cultivos y aprovechamientos prov. Almería, 1982)

El desarrollo económico alcanzado lo hemos considerado bajo para el caso de Fuente Vermeja, incluyendo Vera y La Pernera, a pesar de que no contamos para ellos con restos materiales que evidencien explotación económica. Lugarico Viejo por su parte, alcanzaría un nivel intermedio si consideramos como contemporánea al nivel argárico la escoria encontrada en una vasija que mencionan los hermanos Siret $(1890,100)$ y la aparición de marfil (ibidem). El único hábitat de nivel alto sería ciertamente El Argar a la vista de los restos y evidencias arqueológicas del hábitat por sí mismo, y al margen de las consideraciones que puedan hacerse en torno a los enterramientos y la riqueza diferencial en los ajuares de la necrópolis.

Como hemos informado, los recursos agrícolas eran los mismos para los tres asentamientos (Lugarico Viejo, Fuente Vermeja y El Argar) y en los tres la agricultura en los procesos de sementera, recolección y transformación aparece plenamente desarrollada. En función de las especies presentes en estos yacimientos podemos deducir una explotación cerealista y de regadío en El Argar. La misma intensificación de la producción mostraría Lugarico Viejo en que se alterna el cereal con leguminosas. Sin prejuzgar esta diversidad de productos como muestra de un aumento de población sino como estrategia adaptativa. Fuente Vermeja se dedicaría a una agricultura extensiva de cereal.

En esta cuenca hidrográfica no existe tampoco una posición espacial preferente respecto al posible aprovechamiento de filones metalíferos. Tal vez una mayor proximidad de Lugarico Viejo y Fuente Vermeja al cobre de la Sierra de Bédar frente al Argar.

Una vez más, podemos ver de nuevo como El Argar, alejado de los criaderos de metal, ha desarrollado toda la cadena productiva para la obtención de útiles-armas y adornos metálicos. Para su extracción los habitantes contaban con picos, mazos percutores; crisoles y moldes denotan la actividad metalúrgica aunque no contemos con escorias.

En torno a esta apreciación han girado las hipótesis más sugestivas y argumentadas acerca de la complementariedad interasentamientos, suponiéndola incluso entre aquellos que se localizan 
en distintas cuencas hidrográficas, introduciéndose matizaciones últimas de esta situación en términos políticos. Así verbigracia lo hace Corral Cañón $(1984,202)$ "Los mineros del Argar se trasladaron a otras zonas para obtener el mineral, zonas dominadas por otros yacimientos principales pero a su vez "sometidos" al control del yacimiento epónimo del Argar". Lull $(1983,254)$ obviando la existencia de picos, mazas y percutores para la extracción de mineral, afirma que el primer tratamiento del mismo se realizaría en otro lugar, ello argumenta su defensa del tráfico comercial, controlado efectivamente por este yacimiento, con lo cual justificar la existencia de una superestructura política.

En primer lugar, podemos exponer como reflexión que El Argar se encuentra más cercano a la Sierra de Bédar que a los filones de Sierra de Almagro o Almagrera. Sólo un análisis de los componentes traza, en cualquier caso, podría determinar la procedencia de la materia prima utilizada para la fabricación de útiles metálicos y aún dudamos de la posibilidad de que estos análisis sean determinantes por las dificultades de adscripción a uno u otro de los criaderos tal y como señala Rovira $(1990,115)$. ¿¿n función de qué argumentos existe un cambio de las fuentes de abastecimiento de la Sierra de Bédar en un primer momento a la sierra de Almagro después? ¿Cómo puede esgrimirse el agotamiento de los recursos mineros de la primera? tal y como ha defendido Lull $(1983,267)$.

De otro lado, żcon qué resortes de poder cuenta la comunidad de El Argar para controlar el tráfico comercial, si no aceptamos el aprovechamiento directo de minerales, frente a un poblado como Fuente Alamo que alcanza en nuestra opinión el mismo grado de desarrollo que aquel? Entendemos que el adelanto de los medios productivos agrícolas es el mismo en un yacimiento que en otro, esto es, Fuente Alamo es autosuficiente en productos obtenidos del trabajo de la tierra y por tanto no necesitaría los supuestos excedentes cerealísticos del Argar .¿Constituiría la base del poder político la élite militarista que denota el ajuar de las necrópolis según Gilman y Thornes $(1985,187)$ ?

Por otra parte ¿̨cómo explicamos la aparición de escorias en una vasija en el asentamiento de Lugarico Viejo? La admisión de esta evidencia como contemporánea del mundo argárico, ya que los hermanos Siret no son explícitos en su clasificación cultural, supondría una independencia en la producción metalúrgica para este hábitat. ¿Conlleva esta situación también un control político de Lugarico Viejo sobre los asentamientos de la cuenca del Bajo Almanzora? o jexiste, ya que no se supone una extracción independiente del mineral, unos canales de redistribución del mismo en bruto? ¿Por qué entonces en Fuente Vermeja no existen restos de actividad metalúrgica y tan sólo los productos finales?

Efectivamente, pudiera ocurrir que la comercialización de objetos manufacturados especialmente de oro y plata con funciones de prestigio, o mineral en bruto, con mayores dificultades de transporte, no fueran excluyentes y ambas mercaderías circularan por un territorio en el que hemos podido comprobar que la disposición espacial de los distintos hábitats tiende a un control efectivo del mismo. Pero jen qué dirección espacial se ejerce este control? Fuente Vermeja y Lugarico Viejo dominan visualmente y de manera efectiva la zona situada al Este de ambos yacimientos, de tal forma que Lugarico Viejo controla El Argar. Este hábitat supervisa de forma eficaz el paisaje al Sur-Sureste del mismo. Esto es, el curso del río Antas. Este río constituye una vía natural de penetración desde la costa. El emplazamiento de El Argar podría tener un carácter estratégico en orden a controlar esta posible ruta comercial y por otro lado teniendo en cuenta la capacidad productiva agrícola de los terrenos adyacentes. ¿Cómo es posible explicar entonces un control de las rutas de comunicación por donde de forma tácita discurre el abastecimiento de 
mineral si El Argar ni siquiera controla visualmente ni vislumbra aún estas vías? La situación óptima para este control sería aquella que vislumbrara el SW. de acceso a Sierra Cabrera o el Norte con la Sierra de Almagro, o el NE. con sierra Almagrera.

¿Cómo ejercer el dominio político?.¿¿Debemos pensar en una fuerza militar humana organizada que efectuaría el traslado o que se apostaría en las distintas rutas? ¿Cómo demostrarlo arqueológicamente?

Dejaremos ahora, por el momento, las objeciones que pudieran argumentarse en contra de un dominio político de El Argar sobre los yacimientos del entorno. Creemos será clarificador el análisis que hemos realizado para los asentamientos de la Cuenca del Bajo Almanzora. De esta forma será factible apreciar que el desarrollo de estos yacimientos próximos a recursos mineros potencialmente explotables fue el mismo que en El Argar. De otro lado, en lo que respecta a la simultaneidad en el desarrollo de estos asentamientos, tanto Fuente Vermeja como Lugarico Viejo representarían los inicios de la cultura. Bosch Gimpera (1975,394-395) considera a ambos pre o protoargáricos. Conclusión reafirmada por Lull (1983, 248-252). Martínez Santa Olalla (Et Alii, 1947,17) y Arribas $(1968,37)$ abogan, sin embargo, por una cronología del Bronce Pleno para Lugarico Viejo. Mientras que Walker $(1979,124)$ considera que es campaniforme.

El caso de El Argar resulta esclarecedor para la sistematización cronológica de toda la cultura. Iniciaría su poblamiento en un momento calcolítico perdurando hasta el 1400-1300 a.C. (Lull,1983, 263-265). La problemática de esta datación, dado que no se cuenta con referencias estratigráficas puede seguirse en Martínez Navarrete (1989,398 y ss). Por su parte La Pernera, datada en función de los ajuares de sus sepulturas, correspondería al Bronce Pleno (Lull, $1983,250)$.

\section{CUENCA DEL BAJO ALMANZORA}

El conjunto de yacimientos elegidos, Cabezo de San Miguel, Herrerías-Almizaraque, Fuente Alamo y El Oficio presentan una amplia cronología, dentro de su coexistencia en determinados momentos. Herrerías-Almizaraque sería el primero en surgir, datándose niveles calcolíticos mediante C-14 en el 1860 a.C. y 1910 a.C. en Almizaraque confirmándose las primeras impresiones de los hermanos Siret.

Los tres hábitats restantes muestran una fase argárica como inicio, y culminan en el Bronce Final. Así Cabezo de San Miguel según Siret $(1890,137)$ y Carriazo $(1975,755)$.

El problema es el momento argárico reflejado en el caso de El Oficio. Bosch Gimpera $(1954,49)$ lo limita a una fase arcaica entre 1800-1600 a.C. (periodo de formación de Lull o Argar A). Sin embargo Lull $(1983,244)$ considera su inicio en el momento de apogeo, esto es, en el 1600 a.C.

Fuente Alamo es el único yacimiento, del grupo que estudiamos, que cuenta con una estratigrafía y dataciones para cada uno de los periodos con C-14. Esta secuencia estaría constituida por 5 momentos: Argar Al,A2,Bl,B2 y Bronce Tardío. Contándose con una datación para el Argar A del $2020 \pm 90$ al $1650 \pm 70$ y para el Argar B la fecha más antigua recogida sería del $1620 \pm 60$ siendo la más moderna del 1340 180 . (Schubart y Arteaga 1986;1983).

En los cuatro yacimientos estudiados (FIG.3) Cabezo de San Miguel, Herrerías-Almizaraque, Fuente Alamo y el Oficio, observamos una dipolaridad dos a dos. Si Herrerías-Almizaraque y Cabezo de San Miguel alcanzan un crecimiento primario, ateniéndonos a los escasos datos argáricos proporcionados, sin embargo Fuente Alamo y El Oficio son las cabezas visibles del entrama- 
do en esta cuenca hidrográfica, los restos materiales recuperados son explícitos acerca de la calidad de las actividades desempeñadas; excedentes de producción agrícola se infieren en ambos (Siret, 1890: Schubart y Arteaga, 1978, 1980, 1981, 1983, 1986).

Tal vez sería necesario insistir en que creemos que los restos arqueológicos evidencian el desarrollo, no sólo de la producción metalúrgica, sino también agrícola, para El Oficio y Fuente Alamo. Encontramos un paralelismo en tanto en ambos se localizan azuelas, dientes de hoz, molinos y especies de consumo (cerealísticas en el Oficio y hortícolas en Fuente Alamo) así como estructuras para el almacenamiento. En la explotación mineral encontramos fehacientemente testimonios de explotación minera, útiles metalúrgicos incluidos moldes y productos manufacturados, así como una concentración de la actividad en determinados espacios, en el caso de El Oficio.

Convendría tener presente que no hemos llevado a cabo, a lo largo de todo el estudio, una valoración cuantitativa de los restos materiales encontrados, por ser esta poco menos que imposible puesto que no son explícitas en las respectivas publicaciones. Por tanto, las aproximaciones no pueden ser todo lo objetivas que quisiéramos y se reducen a las valoraciones "escasos" o "abundantes", aún sin obviar algunos datos numéricos. El motivo por el cual hemos hecho esta matización previa no es gratuito porque gran parte de las afirmaciones acerca de la orientación económica de los yacimientos que tratamos se basan en estos parámetros.

Indudablemente, sopesar en función del número de restos la importancia mayor o menor de una u otra actividad productiva ayudaría a una mayor comprensión de la estuctura argárica, pero creemos que dado el conocimiento que tenemos de la mayor parte de los yacimientos las hipótesis a las que puede llegarse no son contrastables ni concluyentes aunque sean aproximativas.

Tras esta premisa, retomando estos dos yacimientos (El Oficio y Fuente Alamo) en los que contamos con mayor información, queremos reproducir fielmente las valoraciones que se han publicado sobre los mismos, dado que concretamente Fuente Alamo se erige en caballo de batalla a la hora de demostrar la existencia de una superestructura política estatal. Sirvan como ejemplo estas líneas de Schubart y Arteaga $(1986,305)$ "en torno al núcleo capital de el Argar funcionaba una organización estatal. No ciertamente una mera "jefatura" como pudiera pensarse, sin la demostración de unos datos objetivos, como los que aporta Fuente Alamo probatorios de la forma en que se hallaba establecida la dependencia entre poblados".

Las bases que se argumentan para esta conclusión serían, en primer lugar, la inexistencia de instrumentos para la roturación y la tan repetida "escasez de piezas dentadas para hoces" (Schubart y Arteaga 1983c, 60;1986,301; Lull,1983,235) frente a la gran acumulación de molinos de mano para la conversión en harina. Si a ello sumamos la inexistencia de silos (Schubart y Arteaga 1986, 301) y el paisaje de monte bajo en las cercanías del poblado, la resolución es tajante: el cereal se transportaba al yacimiento desde otros lugares próximos al valle. Sin embargo, estimamos que necesariamente debemos hacer observaciones a esta primera conclusión, dado que los datos pueden ofrecer otra lectura o valoración. De un lado contamos, contradictoriamente a lo expuesto más arriba, con azuelas (Siret 1890 Lám. 65, Schubart y Arteaga 1978 fig. 12 h). Su presencia ya es por sí misma significativa, puesto que si se reconoce un hábitat montañoso para Fuente Alamo y están documentadas, señal ineludible de la preparación de la tierra si lo contrastamos con Lugarico Viejo o Fuente Vermeja próximos a la vega misma del Jauro-Antas en donde no están presentes (quizá porque los terrenos mullidos de la vega no las necesitaban). 
La abundancia/escasez de piezas de hoz frente a molinos de mano es algo que no podemos valorar y resulta totalmente ambigua su comparación con otros yacimientos para los que no existen datos cuantitativos. En aquellos que sí existen, como en El Argar para el que se citan "más de quinientos útiles", no se especifica la distribución numérica para algunos instrumentos y de la denominación de otros útiles, como las piezas de hoz, se puede dudar (Martínez Navarrete, 1989,419). De todas formas, tan sólo por el tamaño de los dos instrumentos, podemos ver claro que la posibilidad de extravío (en la excavación arqueológica) como también sostiene Martínez Navarrete $(1989,417)$ es mayor para las piezas de hoz frente a la contundente volumetría de un molino de mano. Habría que considerar también el volumen de población y el número de objetos necesitados para una misma cantidad de cereal obtenida.

Choca, por otra parte, que se aprecie la inexistencia de silos como prueba de un abastecimiento externo de grano. Prácticamente ninguno de los yacimientos que tratamos dispone de éstos, es más sólo se han reconocido por los hermanos Siret en el El Oficio, en forma de almacenes en la parte inferior de las casas y el mismo Argar no los posee, aunque está clara la orientación agrícola del mismo. Resulta también contradictorio que a la vez Schubart y Arteaga reconozcan funcionalmente como hórreos las construcciones de planta circular que aparecen en Fuente Alamo (1986,305).

Por último, con respecto al desarrollo de la actividad agrícola merecen una atención especial los recursos edafológicos del yacimiento que tratamos (Fuente Alamo). La consulta del Mapa de Cultivos y Aprovechamientos de la Provincia de Almería, 1982, nos muestra la existencia de suelos pardo-calizos (inceptisoles), para Fuente Alamo y El Oficio, que retienen bien la humedad y facilitan el enraizamiento de las plantas. Estos suelos son los que encontramos en el caso del Argar pero Fuente Alamo cuenta con la ventaja añadida de suelos de vega (entisoles) en sus cercanías. Si a ello sumamos una mayor pluviometría, menor temperatura y menor escabrosidad (Gilman y Thornes, 1985, 173 y ss) para Fuente Alamo frente al Argar, creemos que la actividad agrícola sería incluso más rentable en el primero que en el yacimiento que da nombre a la cultura, aunque en Fuente Alamo existiera mayor distancia a los terrenos de cultivo.

De igual forma abogan por la existencia de tierras de cultivo la especie de ruderal vegetación aportada por los análisis realizados por Schubart y Arteaga (1986,300). Las malas hierbas compiten con los cultivos. Estos mismos autores señalan incluso su presencia en la actualidad al pie de la pendiente de Fuente Alamo sobre los suelos más ricos del lugar. ¿Por qué no aceptar entonces, que aunque no en el terreno más próximo al poblado pero sí en las cercanías, fueron explotadas especies cerealísticas y de regadío? ¿Por qué depender del abastecimiento de grano de el Argar, si éste podía ser producido en terrenos más rentables y controlados visualmente desde Fuente Alamo?

En otro orden de cosas, el desarrollo de la ganadería en Fuente Alamo está también subordinado por sus excavadores a la dependencia de otros poblados, así el ganado vacuno era "enviado desde otro lugar" (ibidem,301). Pensar que fuera el Argar el que suministraba este ganado nos parece aventurado, puesto que debería contrastarse con la presencia del mismo en este yacimiento, además de en mayor abundancia incluyendo también otras especies que no aparecen. La presencia de Bos Taurus en el Argar la señala Navarro Mederos $(1983,46)$ quien a su vez la cita de Arribas $(1967,40)$ pero su presencia se anota en las tumbas y no se contrasta la presencia de ganado porcino y otras especies que sí aparecen en Fuente Alamo.

Aquellos bóvidos de Fuente Alamo eran además adultos por lo que se supone fueron utilizados como fuerza de arrastre en faenas agarícolas o de transporte. Por contrapartida, los ovicapridos eran 
consumidos jóvenes, esto es, su carne era el motivo del sacrificio. ¿¿Habría que pensar también que las especies de Bos Taurus y Cabra del Oficio procedían también de otro yacimiento?

El tercer punto que subraya, en opinión de los autores que venimos citando, la complementariedad interasentamientos es que "no se desarrollaba una floreciente metalurgia" en Fuente Alamo (Schubart y Arteaga 1986,302 y 304; Ibidem 1983 c, 61). En definitiva, se haría un tratamiento primero del mineral, tras su extracción. Se obtendría la mena metálica y se trasladaría reducido hacia otros asentamientos, presumiblemente hacia el valle. Hemos de advertir como primera matización que si tal actividad minera fuera exclusiva, como parece deducirse de las afirmaciones arriba expuestas ¿no serían numerosos los percutores, mazos y picos en Fuente Alamo? Por el contrario no tenemos constancia de los mismos en el yacimiento. Podría objetarse que su función podrían haberla desempeñado los "martillos" que mencionan los Siret (1890, lám.88). Schubart y Arteaga sugieren que tal función la cumplirían los objetos de piedra denominados por su forma ídolos fálicos $(1986,304)$ que son en realidad los encontrados por los Hermanos Siret. Es indudable que resulta comprometida la explicación de la función de los siempre llamados picos, mazos y percutores y que más bien podríamos hablar de multifuncionalidad sin excluir la explotación minera .

De otro lado volvemos a traer a colación los ya mencionados útiles mineros del Argar que suponen la explotación directa de las minas de la Sierra de Bédar o de la de Almagro en cuyo caso podríamos hablar de pactos o alianzas, si este territorio lo consideraran como propio los habitantes de Fuente Alamo cuestión difícil de dirimir desde el punto de vista arqueológico. Estos útiles son por lo demás y en los términos ambiguos que expresábamos "abundantes" según Lull $(1983,254)$ en El Argar, luego la relación coste-beneficio en relación al desplazamiento hacia las vetas de mineral se decantaría favorable a su producción. Esto es, sería más rentable la explotación directa, a pesar de la distancia, que el intercambio presumible por grano.

Con respecto a la transformación metalúrgica, la presencia de mena metálica de cobre, escorias y moldes de fundición, así como productos manufacturados, supondría que todo el proceso metalúrgico se realizaba en Fuente Alamo.

Bien es verdad que la variedad de objetos manufacturados no responde a los tipos de moldes encontrados (de varillas), argumento de Schubart y Arteaga $(1986,302)$ para suponer que elementos como los puñales o hachas fueron obtenidos mediante comercio, llegando incluso a negar la existencia de moldes. Queda pues tener presente que los moldes se habrían fragmentado de tal forma que fueran irrecuperables en el registro arqueológico, o admitir la existencia de este comercio. O sea, considerar un abastecimiento propio de Fuente Alamo de los objetos más rudimentarios de menor complejidad técnica, mientras que los productos más elaborados serían proporcionados por otro asentamiento más adelantado técnicamente: El Oficio o El Argar equidistantes aproximadamente a Fuente Alamo. En El Oficio se han encontrado moldes, y no escorias como en El Argar. ¿ Obtendría también por ello El Oficio el metal beneficiado de Fuente Alamo como se ha sostenido para El Argar? La cercanía de la Sierra Almagrera a El Oficio nos permite desechar esta hipótesis así como la presencia de picos y martillos mineros en este yacimiento.

Pero la razón aducida para este comercio (inexistencia de un tipo de molde para cada tipo diferente de útil hallado en la necrópolis) plantea una cuestión, porque entonces tendríamos que justificar la existencia de un yacimiento aún inédito o relaciones con otros ámbitos mediterráneos para explicar la aparición de determinados objetos presentes en algunas tumbas, por ejemplo la diadema del Argar o las espadas, puesto que los moldes no han sido hallados en ningún yacimiento de la cultura, que tengamos noticia. 
Tras estas dudas expuestas y no resueltas, somos conscientes de la necesidad de una revisión más exhaustiva de los materiales aparecidos en cada uno de los hábitats, no tanto para establecer tipologías como paralelos así como la fuente de materias primas. No menos importante serían nuevas excavaciones que permitan obtener estratigrafías para concluir cronologías aún no definitivas para el ámbito argárico.

Finalmente, queremos hacer una última precisión en torno al trabajo metalúrgico y explotación de la plata en Fuente Alamo. Resultaría paradójico de una lado sostener que la comunidad que habitaba este asentamiento la explotó directamente y no reconocer que la misma actividad pudo ser desarrollada por los habitantes del Argar. Ambos yacimientos se encuentran equidistantes con respecto a los filones de Sierra Almagrera. La distancia en línea recta para Fuente Alamo es menor, pero la orografía del terreno supondría el mismo tiempo empleado aproximadamente que en el caso de El Argar. Por tanto deberíamos preguntarnos por las relaciones que necesariamente habrían de establecerse con El Oficio, yacimiento que controla Sierra Almagrera; pactos o alianzas debían jugar un buen papel al respecto. Si por el contrario optamos por la existencia de una redistribución bien del metal en bruto o de los productos manufacturados hemos de explicar cual era el objeto de intercambio. El metal en bruto, si creyéramos que Fuente Alamo no llevaba a cabo la transformación, es difícil fuera objeto de comercio por los mayores costes de transporte.

En cuanto al objeto de intercambio recíproco, si tenemos en cuenta la afirmación de los investigadores de Fuente Alamo, este yacimiento no podría proporcionar el grano suficiente a el Oficio. Es más, si como estimamos, Fuente Alamo, aunque no deficitario si autosuficiente desde el punto de vista agrícola y con excedentes, podría haberlo suministrado a El Oficio. Pero este último yacimiento resulta que desarrolla con creces la producción agrícola luego no existiría la necesidad de grano. ¿Debemos recurrir entonces a situaciones de carencia extrema por catástrofes climáticas para explicar el abastecimiento de grano de Fuente Alamo al Oficio? Si lo intentáramos tendríamos que valorar que de existir malas cosechas en El Oficio que requirieran importación de grano esta situación también acaecería en Fuente Alamo dadas las condiciones equiparables entre los dos yacimientos de edafología y climatología. Lo mismo podría aducirse con motivo de las plagas dada la proximidad de ambos.

En definitiva, opinamos que la exclusividad de este metal de plata o de oro en determinados ajuares de las respectivas necrópolis aboga, bien por un intercambio selectivo (de prestigio), bien por una explotación ocasional directa de Fuente Alamo o El Argar al servicio de determinados intereses (con un mayor coste en función de la distancia). No podemos simplificar los intercambios, de existir de manera regular entre dos asentamientos, sino más bien hablar de una red de alianzas. Esta puede ser entendida tal y como la postula Mathers (1984), los contactos intercomunitarios podrían ser múltiples en función de una economía de bienes de prestigio. Ello no implica economías mutuamente dependientes, ni una figura política central.

\section{CONSIDERACIONES FINALES Y CONCLUSIONES}

Queremos en este momento, una vez analizadas las distintas cuencas en las que se ubican los distintos poblados, mostrar cuantitativamente el tanto por ciento de yacimientos en los que aparecen representadas las distintas actividades económicas, con el fin de poder valorar globalmente el desarrollo económico alcanzado. Para que sea más explícito y digno de crédito el porcentaje representado, hemos distinguido entre las cantidades que significan la presencia de actividades en aque- 
llos yacimientos de los que tenemos una mayor documentación de un lado, y de otro los porcentajes del conjunto total en los que se incluyen también aquellos yacimientos que sólo tenemos localizados en el espacio y con una insignificante mención con respecto a evidencias de carácter económico (molinos o recolección). De esta forma los yacimientos más documentados consideramos que son: El Oficio, Cerro de Enmedio, El Argar, Gatas, Fuente Vermeja, Lugarico Viejo, Peñón de la Reina, El Picacho, Fuente Alamo, (aquellos cuya información valorábamos como excelente, buena, suficiente o poca). Entre los segundos yacimientos que intervienen en el porcentaje total y que aportan mínima información (deficiente) tenemos: Cerro del Fuerte, Cabezo San Miguel, Herrerías-Almizaraque, La Pernera, Vera, Teresa, La Panalera, La Losa, La Risca, Cerro Castellón, Peñicas Negras y Cerro del Castillo.

\section{Actividades de Recolección}

Frutos y moluscos

\section{Actividades Agrícolas}

Azuelas

Dientes de hoz

Molinos

Alguna

Proceso total

\section{A.Cinegéticas}

A.Ganaderas

A. Metalúrgicas-Mineras

Picos

Transformación

Utiles/Armas o adornos

Algun indicio

Proceso total

\section{A.Transformación}

Textil

Hueso

Madera

\section{Objetos Exóticos}

Excedentes

\section{Cjto de yacs. mejor documentados} $77,7 \%$

$44,4 \%$
$88 \%$
$88 \%$
$100 \%$
$55 \%$

$66,6 \%$

$66,6 \%$

$55 \%$

$88,8 \%$

$88,8 \%$

$100 \%$

$55,5 \%$

$88,8 \%$

$77,7 \%$

$77,7 \%$

$44,4 \%$

$44,4 \%$
CjtoTotal de yacs. $42,8 \%$

$19 \%$

$38 \%$

$52 \%$

$57 \%$

$23,8 \%$

$28,5 \%$

$28,5 \%$

$28,57 \%$

$42,8 \%$

$38,09 \%$

$47,6 \%$

$23,8 \%$

$38,09 \%$

$33,3 \%$

$33,3 \%$

$19 \%$

$19 \%$

De modo explícito, podemos ver como las actividades de recolección y de carácter agrícola están ampliamente representadas, señal de una orientación agrícola y de autoabastecimiento en la mayor parte de los casos. La baja cifra que se presenta con respecto al desarrollo total del proceso agrícola, se debe sin duda a la escasa representación de las azuelas. La explicación podría estar en 
que la mayor parte de los asentamientos se encuentra en las ricas vegas de los ríos, lo que supone que no sería necesario el mullido de los suelos para facilitar el enraizamiento de las plantas dado el carácter sedimentario del terreno. Se alcanza la misma proporción de yacimientos que poseen dientes de hoz que los que poseen molinos, en el caso de los hábitats de los que poseemos una mayor información, lo cual reafirma la orientación que seguíamos líneas atrás acerca de la producción agrícola in situ y no del traslado o intercambio de cereal desde unos lugares a otros. En cuanto al global de yacimientos es significativo que, incluyendo aquellos que han proporcionado nula o escasa información, el porcentaje de molinos aumente respecto al de dientes de hoz. Esto, es los dientes de hoz están, en general, escasamente representados y no sólo en el caso de Fuente Alamo.

Con respecto a las actividades cinegéticas y ganaderas observamos que existe el mismo porcentaje de representación en todos los yacimientos, alcanzándose una cifra inferior con respecto a la agricultura. Ello llevaría consigo un menor interés de las comunidades argáricas en esta orientación productiva, aunque también puede obedecer al escaso tratamiento de los restos óseos en las excavaciones de principios de siglo, con lo cual tendríamos mermado el registro y consiguientemente las posibles interpretaciones. En cualquier caso, y puesto que no tenemos las proporciones respecto al hueso trabajado y aquel que no se ha transformado, podemos afirmar que habría un aprovechamiento múltiple de esta ganadería y fauna cazada: se consume la carne y de otro lado se llevan a cabo actividades de transformación de los huesos obtenidos una vez aprovechada la energía calorífica alimentaria. Estos útiles óseos, por otra parte, pudieron ser empleados tanto para el trabajo de la madera como en el textil, también ambos ampliamente representados en el caso de los yacimientos más documentados, aunque comparativamente menos importante que la agricultura si evaluamos el global.

Si valoramos de forma general el desarrollo de la actividad metalúrgica sorprenden los porcentajes alcanzados. El número de yacimientos en los que todo el proceso se ha realizado para el tratamiento, obtención del mineral, beneficio del metal y fabricación de utensilios, es equiparable al número de los mismos hábitats en que la cadena productiva agrícola es completa. Aún de mayor relevancia es que en los yacimientos en que la información es aceptable tienen igualmente representada la actividad de transformación que la de objetos manufacturados. Es por tanto factible considerar que los yacimientos argáricos de la provincia de Almería desarrollaban la metalurgia y además de forma independiente unos respecto de otros. Esta situación sería matizable atendiendo a la menor representatividad de picos, mazos y percutores al igual que las azuelas y en ningún caso creemos fruto de la dedicación exclusiva de determinados yacimientos a la explotación minera, o sea una concentración de la misma en un número reducido de ellos. En primer lugar, como hemos expuesto, porque estos útiles mineros aparecen en lugares alejados de filones metalíferos y en segundo lugar en función de la ambigüedad en la interpretación de estos instrumentos, si bien algunos investigadores consideran que estarían dedicados a la extracción del mineral, otros los clasifican como instrumentos además al servicio de la explotación forestal.

El desigual desarrollo económico alcanzado queda patente en la diferencial aparición del objeto exótico y existencia de excedentes en los hábitats estudiados. El porcentaje es restringido en la valoración global y lo mismo sucede fijándonos en los yacimientos más documentados, siendo no obstante caso representativo de forma general. El hecho de que en un $44 \%$ de los últimos yacimientos aparezcan objetos exóticos y excedentes eleva la consideración de la cultura argárica por encima de su evaluación como un mero precedente del periodo del Bronce Final o de la Edad del Hierro.

Como término de este trabajo, conscientes de la necesidad de una mayor elaboración y profundización en muchos de los aspectos aquí tratados, queremos resumir y hacer explícitas algunas de las conclusiones patentes a las que hemos llegado a través del análisis realizado. 
- En primer lugar, no existe, en nuestra opinión, una estructura compleja de asentamientos, con lo cual deberíamos colocar entre comillas el término de jerarquización que hemos utilizado a lo largo de este trabajo. No encontramos una vertebración en las distintas cuencas hidrográficas, de tal forma que en cada una de ellas aparezcan comunidades múltiples distribuidas en cada uno de los tres grados económicos que propusimos. Por el contrario los asentamientos que comparten un mismo nicho ecológico se polarizan en dos extremos. O están muy desarrollados económicamente hablando o registramos actividades de mero autoabastecimiento. Esto ocurre como ejemplo más representativo en la cuenca del Aguas. De un lado Gatas (nivel intermedio) y de otro apenas constancia de Teresa, la Panalera, Losa, La Risca, Peñicas Negras.. , o en el Bajo Almanzora. Unicamente en la cuenca del Jauro-Antas encontramos presentes los tres niveles; El Argar, Lugarico Viejo, en los grados alto e intermedio, mientras que Vera, La Pernera y Fuente Vermeja sólo se desarrollaron a nivel primario. Pero aún en este caso, si introducimos la variante cronológica, en el periodo argárico pleno habría desaparecido Lugarico Viejo luego la función que podría haber cumplido este poblado deja de ser necesaria, lo mismo ocurre con el Cerro de Enmedio en la cuenca del Andarax.

A esta misma conclusión llegó Corral Cañón $(1984,200)$. El modelo de asentamiento argárico estructurado en tres niveles económicos, sólo se cumplía en el Bajo Almanzora y en la región murciana en las cuencas del Sangonera y Segura. Teniendo en cuenta que el resultado obtenido con respecto al Bajo Almanzora era fruto de la consideración de Fuente Alamo como yacimiento de grado intermedio, frente a la valoración en este trabajo como yacimiento principal.

De otro lado, Chapman (1991,243-44) constata también la existencia tan sólo de dos niveles de jerarquización, atendiendo a las hectáreas ocupadas por los yacimientos argáricos del SE en su conjunto. En su opinión esto denotaría la "inexistencia de una organización estatal".

Debemos destacar también que existe una concentración de los yacimientos más evolucionados en una zona geográfica reducida (el NE de la provincia) en la comarca de Vera, cuestión que debería ser explicada más detenidamente.

No en vano, es precisamente en esta depresión en la que se alcanza la mayor densidad de población, en comparación con la del Sur de Almería y Este de Granada, según los datos calculados por Chapman $(1991,220)$

- No existen ventajas sustanciales desde el punto de vista agrícola de unos yacimientos con respecto a otros. Como hemos repetido a lo largo de este estudio, la potencialidad de los suelos (pardo-calizos en su mayoría) es la misma, optimizada con el asentamiento en los valles de los ríos, en muchos de los casos.

Con ello queda explícito el hecho de que no se buscaron los diferentes emplazamientos en función de la existencia en sus proximidades de un tipo de suelo específico con unas determinadas ventajas productivas. Muchos de los yacimientos cuentan con una ubicación estratégica.

A partir de los trabajos de Chapman condensados en su última publicación (1991), parece evidente una localización de los asentamientos argáricos orientada al aprovechamiento de los recursos hídricos, en comparación con sus antecesores. Aunque sigan siendo discutibles las distintas tecnologías empleadas para su aprovechamiento, así como su contrastación empírica.

- De otro lado y en esta misma línea de los recursos existentes potencialmente explotables, no podemos afirmar la existencia de grupos fundamentalmente mineros. Aquellos yacimientos próximos a estos recursos desarrollaron la actividad agrícola y en toda la cadena productiva en muchos de los casos (Fuente Alamo, El Oficio). En algunos incluso, lejos de existir evidencias del trabajo de explotación minera y dada su situación en el valle, se detecta exclusivamente la aparición de molinos o cereales, pese a la cercanía del mineral (Cuenca del Aguas excepto Gatas). 
No obstante sería imprescindible definir qué consideramos una dedicación "fundamentalmente minera". Puesto que nosotros basamos nuestras observaciones en función de la presencia/ausencia y en la significación en el proceso productivo de aquel resto material que valoramos y no en su abundancia o escasez o en la proximidad o lejanía al recurso en cuestión.

- No hemos podido tampoco demostrar que "la mayoría de los grupos sólo cuentan con uno o dos asentamientos próximos a los filones y el resto basa su producción en la agricultura y ganadería" (LULL, 1983,445). En el caso del Jauro-Antas no hay una situación preferencial para el aprovechamiento y beneficio del mineral. No hay "avanzadillas" mineras y el ejemplo repetido del Argar muestra que a pesar de la distancia se desarrolló todo el proceso, desde la extracción hasta la manufactura de objetos metálicos. La situación es similar para el caso de la Cuenca del Aguas con Gatas. En el caso del rio Andarax, un poblado alejado de la Sierra Alhamilla como el Cerro del Fuerte desarrolla la actividad metalúrgica y no hay evidencias de explotación agrícola.

En aquellos asentamientos en los que existen objetos manufacturados de carácter metálico tenemos evidencias de beneficio del mineral y manufactura del mismo, estén próximos o alejados de las minas excluyendo Fuente Vermeja, pero en este caso podríamos decir que es la excepción que confirma la regla. Como reflejábamos en la última tabla hay una paridad en porcentajes entre desarrollo metalúrgico y desarrollo agrícola, lo que nos lleva, con todas las cautelas, a suponer una minería y metalurgia local e independiente, cuando menos para el caso del cobre, opinión sostenida también, entre otros, por Gilman (1987,27-35).Mientras se encontraba en prensa este trabajo fueron publicados los resultados de la Tesis Doctoral de I. Montero Ruiz (1992a, 1992b), quien aboga por el autoabastecimiento minero-metalúrgico de cada yacimiento, basándose en la abundancia y accesibilidad de recursos y en la presencia del proceso de transformación metalúrgica en la mayoría de los hábitats

Sin embargo, esta afirmación se convierte en un arma de doble filo. Tanto Lull “... bastaría un control político sobre las comunidades vecinas para obtener productos en los que el asentamiento es deficitario..." (1983,253,453), como Corral Cañón (1984,202-203), sostienen precisamente que es esta metalurgia independiente en asentamientos alejados de los criaderos de cobre la que constata o ejemplifica el control político de unos yacimientos sobre otros.

Ahora bien, la cuestión está en demostrar con una base empírica suficiente quién, cómo, y en virtud de qué medios se ejerce esa dirección política.

Para Lull (1983,456 y ss) el papel adquirido por la metalurgia provocará la diferenciación económico-funcional de los distintos poblados, surgiendo el intercambio de alimentos (cereales) por productos metalúrgicos. Las necesidades de transporte, y vigilancia de rutas, en suma de gestión y organización llevarán al poder a un grupo determinado que controlará no sólo la distribución, sino también los recursos.

No obstante, otra vía o explicación sería, para este autor, (LULL, 1983, 453, 265-67) la del desarrollo de una agricultura intensiva que proporcionaría los excedentes necesarios en un momento de aumento demográfico y de erosión y agotamiento de los suelos.

Varias objeciones pueden presentarse, entre otras, al papel otorgado a la metalurgia y la supuesta producción complementaria. Si nos centramos en la primera cuestión, parece evidente un incremento en la producción de artículos metálicos y en la variedad de los mismos en la época argárica. Sin embargo, tal y como lo fundamenta Chapman $(1991,233)$, la innovación tecnológica, que se centró en la metalurgia, se orientó hacia objetos suntuarios (adornos) y armas, pero no se invirtió en la mejora de los instrumentos de producción que permitiera unos mayores beneficios, tampoco se intententaron salvar las dificultades medioambientales. De esta manera, los 
adornos y armas metálicas (objetos de lujo y ostentación) vienen a confirmar, en nuestra opinión, el poder de quien lo detenta, poder político adquirido por otros medios y con otros resortes.Para Montero (1992b) la metalurgia sería una actividad económica secundaría, no especializada que no puede justificar por si misma la existencia de élites dirigentes.

En lo que respecta a la complementariedad, ésta es defendida por Lull, Schubart, o Chapman. Al margen de las reiteradas afirmaciones a lo largo de este trabajo, podríamos resumir nuestra postura: si no existe una especialización agrícola, minero-metalúrgica o artesanal, con todas sus implicaciones, no puede defenderse este tipo de integración económica. No podemos olvidar tampoco las precisiones de Martínez Navarrete $(1989,425)$ cuando apunta que Lull, al afirmar la interdependencia de los distintos yacimientos, pasa por alto el punto de partida de su trabajo, esto es, reunió en conjuntos aquellos yacimientos que compartían el mismo nicho ecológico.

Para finalizar, como comentábamos al comienzo de estas líneas, nuestro interés se ha centrado de forma limitada en una cuestión concreta (la estructura económica) que nos ha permitido clarificar, tras la aplicación de una determinada propuesta metodológica, no la única planteada para el mismo objetivo, un presupuesto (la especialización económica de los asentamientos argáricos) sobre el que se ha fundamentado todo el complejo entramado social que se defiende para esta cultura.

Nuestro estudio no es completo y dentro de nuestros intereses estaría el análisis de la posible especialización funcional dentro de cada hábitat (en cuanto a los restos constructivos) así como la revisión y estudio de los restos funerarios. La correlación del grado de desarrollo económico con las posibles estructuras de producción, construcción de defensas artificiales complejas, planteamiento urbanístico, vías de comunicación u orientación estratégica del poblado de un lado y todo ello conjugado con el conjunto ergológico de las tumbas valorándolo cualitativa y en este caso también cuantitativamente, podría medir la validez de las conclusiones a las que hemos llegado para esta provincia de Almería.

Quede también claro que podrían hacerse múltiples objeciones a nuestro trabajo, en cuanto a la coexistencia de los distintos yacimientos, desde el momento en que no es posible afinar más en la cronología, dado el estado actual de la investigación.

Contamos con el problema necesario de revisión de la secuencia cultural (Martinez Navarrete, 1989, 458-77). Consultando la información existente, tan sólo hemos advertido en dos casos un corto periodo que abarcaría la primera fase de la cultura (Cerro de Enmedio y Lugarico Viejo) apreciaciones que hemos incluido en nuestro estudio, pero para muchos de los yacimientos peor documentados carecemos de una delimitación de la secuencia cronológica.

Al hilo de estas consideraciones sirvan estas líneas para solicitar la necesidad de un estudio crítico y renovador de este periodo concreto. Ante todo, tarea ingente pero concluyente, serían las nuevas campañas de excavaciones con criterios tales como los desarrollados en el Proyecto Gatas (Chapman Et Alii, 1987) o la labor llevada a cabo por el Instituto Arqueológico Alemán. De otro modo, dada la información disponible, todas las conclusiones emitidas, incluidas las aquí presentes, son cuestionables.

Agradecimientos: Al Dr. Sánchez Meseguer y a todos los colaboradores del Proyecto Arxeos, con los que hemos trabajado los dos últimos años, y sin los que este trabajo no hubiera sido posible.

Madrid, 1989 


\section{BIBLIOGRAFIA}

Algarra Esteban, R.,1952: "Noticias sobre algunos yacimientos argáricos", Noticiario Arqueológico Hispánico I, 1-3, Madrid, pp.30-37

... 1955: "Noticias sobre algunos yacimientos argáricos", Noticiario Arqueológico Hispánico II,1-3, Madrid, pp.184-188.

Arribas, A., 1953-54, "Nuevos hallazgos en la provincia de Almería", Ampurias XV,XVI, Barcelona, pp. 342-345.

... 1967: "La edad del Bronce en la península Ibérica", Raíces de España, Gómez Tabanera (ed), Madrid,pp. 85-108.

... 1968: "Las bases económicas del Neolítico al Bronce", Estudios de economía antigua de la Peninsula Ibérica, Barcelona, pp.33-60.

BosCh GIMPERA, P., 1954: "La edad del Bronce en la Península ibérica", AEArq, XXVII, Madrid, pp.45-92 ... 1975: Prehistoria de Europa, Madrid.

Carriazo, J. DE Mata, 1975: "La Edad del Bronce”, R.Menéndez Pidal (ed), Historia de España, Tomo 1.1, Madrid, pp 755-852.

Catalogo de suelos de Andalucia, 1984: Monografias del Medio ambiente, 3, Sevilla.

Corral CAÑon, M.,1984: "Modelos de asentamiento argáricos", Coloquio sobre distribución y relaciones entre asentamientos, Teruel, vol.3, pp.197-211.

Chapman, R. W., 1978: "The evidence for prehistoric water control in S.E. Spain", Journal of Arid Environments, l, pp.261-74.

... 1982: "Autonomy, ranking and resources in Iberian Prehistory", C.Renfrew y S.Shennan (eds), Ranking Resource and Exchange,Cambridge, pp. 46-51

... 1991: La formación de las sociedades complejas. El Sureste de la península ibérica en el marco del Mediteráneo occidental,Barcelona

... et alii, 1987: Proyecto Gatas. Sociedad y economía en el S.E. de España 2500-800 a.n.e., Bar Internacional Series, 348, Oxford.

Diaz Alvarez, J. R., 1981: Estudio del potencial de los suelos agrarios de la provincia de Almeria, Madrid

... 1984: Atlas geográfico provincial comentado de Almeria, Almería.

GALAN, C. et alii, 1988: "Aplicaciones de inteligencia artificial y "sistemas Expertos" a la arqueología.Un "experto" en economía del III milenio de la Península Ibérica”, Cuadernos de Prehistoria y Arqueología U.A.M.,15 pp.69-105.

Gilman, A., 1981: "The development of social stratification in Bronce Age Europe", Current Anthropo$\log y, 22$, pp.1-23.

... 1987: "El análisis de clase en la Prehistoria del S.E.", Trabajos de Prehistoria, 44, pp.27-35.

... y Thornes, J. B., 1985: Land use and prehistory in Southeast Spain, Londres, The London Research Series in Geography,8.

LeIRA JimeneZ, R., 1987: "El yacimiento argárico del Oficio, Cuevas, (Almería)", Trabajos de Prehistoria, 44, pp.201-223

LuLL,V., 1983: La cultura del Argar, Barcelona, Akal

... y Estevez, J., 1986: "Propuesta metodológica para el estudio de las necrópolis argáricas", Homenaje a Luis Siret 1934-1984, Sevillla, pp.441-52.

Mapa de Cultivos y aprovechamientos de la PRovinCia DE Almeria, 1982: Escala 1:100.000

Martinez Navarrete, M. I., 1989: Una revision crítica de la Prehistoria española: La Edad del Bronce como paradigma, Madrid, Siglo XXI 
Martinez Padilla, C., 1986: "El Argar y la argarización en el occidente de la provincia de Almería. La cuenca del río Nacimiento-Andarax”, Homenaje a Luis Siret, pp. 304-314.

Martinez Santa Olalla, J. et alii, 1947: Excavaciones en la ciudad del Bronce Mediterráneo II de la Bastida de Totana (Murcia), Informes y Memorias, 19, Madrid.

MATHERS, C., 1984: "Linear progression inflation and prestige competition:2nd milleniun transformations in South-East Spain”, WH.Waldren et alii (eds), The Deya conference of Prehistory,Oxford, pp. 1167-1196

Molina, F. et alii, 1980: "El Cerro de Enmedio un poblado argárico en el valle del río Andarax", CPUG, 5, pp.157-174

Montero Ruiz, I., 1992 a: "Estudio arqueometalúrgico en el Sudeste de la Península Ibérica". Colección Tesis Doctorales, Editorial de la Universidad Complutense, Madrid.

.. 1992 b: "La actividad metalúrgica en la Edad del Bronce del sudeste de la Península Ibérica: Tecnología e interpretación cultural", TP, 49, pp. 189-209.

Navarro Mederos, F., 1983: "La explotación del territorio en la Península Ibérica durante el Bronce Pleno. Aproximación a su estudio", Tabona, IV, Universidad de la Laguna, pp.29-84.

RAMOS, A., 1981: "Interpretaciones secuenciales y culturales de la Edad del Cobre en la zona meridional de la Península Ibérica. La alternativa al materialismo cultural”, CPUG, 6, pp.242-256.

Rovira, S., 1990: Técnicas de investigación arqueometalúrgica, Ciencia y técnica al servicio de la investigación arqueológica. Barrios,J. (ed), Madrid, pp. 106-125.

SChUbarT, H., 1980: "Cerro de Enmedio.Hallazgos de la Edad del Bronce en el Bajo Andarax", CPUG, 5, pp 176-192

... y ARTEAGA, O., 1978: "Fuente Alamo", Madrider Mitteilungen, 19, pp . 23-51.

... 1980: "Fuente Alamo: Excavaciones 1977", N.A.H., 9,Madrid.

... 1981: "Fuente Alamo: Campaña de 1979", N.A.H., ll, Madrid.

... 1983 a,b,c: "Excavaciones en Fuente Alamo. La cultura del Argar", Revista de Arqueologia, números 24, 25, 26, Madrid .

... 1986: "Fundamentos arqueológicos para el estudio socioeconómico y cultural del área del Argar", Homenaje a Luis Siret, Sevilla, pp. 289-307.

SIRET, E. y L., 1890: Las primeras edades del metal en el Sudeste de España, Barcelona.

TAPIA GARRIDO, J. A., 1981: Historia General de Almeria y su provincia, Tomo I, Almería.

WALKER, M. J., 1979: "Neolithic an Chalcolithic pottery of SE. Spain", Australian Studies in Archaeology, 2, pp.104-147. 